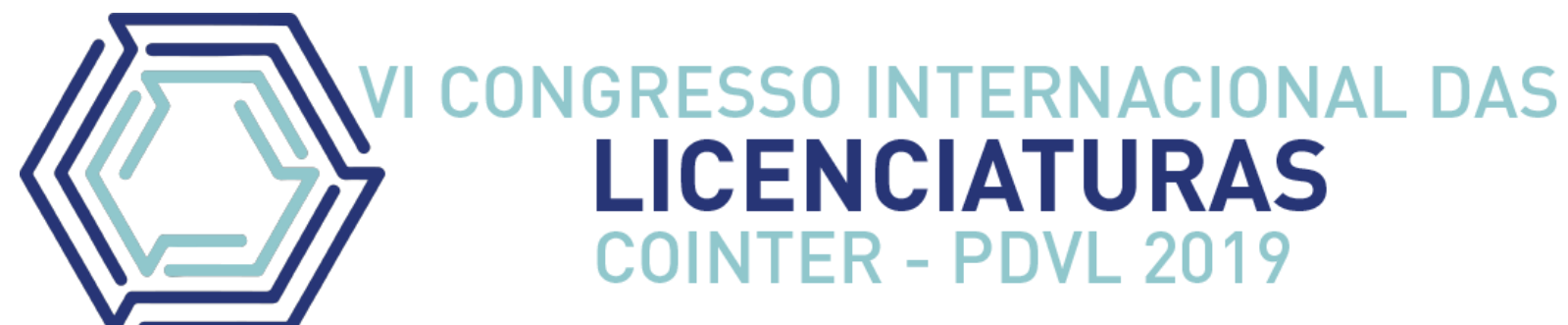

\title{
VIVÊNCIAS DO RESIDENTE DO PROGRAMA DE RESIDÊNCIA PEDAGÓGICA NA ESCOLA DOM MALAN EM SALGUEIRO-PE
}

\author{
EXPERIENCIAS DEL RESIDENTE DEL PROGRAMA DE RESIDENCIA \\ PEDAGÓGICA EN LA ESCUELA DOM MALAN EN SALGUEIRO-PE
}

\section{EXPERIENCES OF THE RESIDENT OF THE PEDAGOGICAL RESIDENCE PROGRAM AT DOM MALAN SCHOOL IN SALGUEIRO-PE}

\author{
Apresentação: Comunicação Oral \\ Edinalva Ana da Silva ${ }^{1}$; Aurelania $\mathrm{M}^{\mathrm{a}}$ de Carvalho Menezes ${ }^{2} ; \mathrm{M}^{\mathrm{a}}$ das Graças Bento ${ }^{3}$
}

DOI: https://doi.org/10.31692/2358-9728.VICOINTERPDVL.2019.0080

\begin{abstract}
Resumo
O presente artigo tem por finalidade apresentar objetivo do Programa Residência PedagógicaPRP e visa a interação entre alunos residentes, professores e escolas para aperfeiçoar a formação dos docentes de cursos de licenciaturas por meio de desenvolvimento de projetos que fortaleçam o campo da prática e conduzam o licenciado a exercitar de forma ativa a relação entre teoria e prática profissional docente, utilizando coleta de dados e diagnósticos sobre o ensino e a aprendizagem escolar entre outras didáticas e metodologias onde busca experiências e estratégias, que propõe uma reflexão sobre benefícios do PRP que induz o aperfeiçoamento da formação prática de professores. Os residentes auxiliarão os professores para que esses pequenos problemas no ensino e aprendizagem sejam amenizados. Oportunizar os residentes a uma visão ampla de como funciona uma sala de aula mostrando de uma certa forma um inicio de uma nova etapa na sua vida profissional onde o mesmo adquire novas experiências e aprimora as suas práticas. Após a inscrição e aprovação do PRP, iniciou-se a primeira fase de ambientação onde conheceu-se a escola no geral, da gestão à cozinha. A segunda fase foi de imersão nas salas de aula, auxiliando os professores e unindo a teoria à prática. Esta fase facilitou o aprendizado dos alunos e proporcionou experiências únicas aos residentes. Este trabalho apresenta projetos desenvolvidos na escola sobre os hábitos alimentares, pois hoje há mais de $50 \%$ dos estudantes que precisam ter uma reeducação alimentar, porque se alimentam muito de produtos industrializados e também das dificuldades que as crianças enfrentam em sala de aula regular onde mostra as dificuldades e as superações. Este trabalho é de natureza qualitativa e contou com o apoio bibliográfico de autores como FERREIRO (1987), LIBÂNEO (1996), VEIGA (2004), ZEICHNER e CAIADO (1998).
\end{abstract}

Palavras-Chave: Programa Residência Pedagógica, Formação dos docentes, Aperfeiçoamento.

\footnotetext{
${ }^{1}$ Graduanda em Pedagogia, FACHUSC, silvaedinalva885@gmail.com

2 Pedagogia, FACHUSC, lelamenezesluiza@yahoo.com.br

${ }^{3}$ Mestre, Universidade Católica de Pernambuco, professoragracabento@hotmail.com
} 


\title{
Resumen
}

Este artículo tiene como objetivo presentar el objetivo del Programa de Residencia Pedagógica - PRP y tiene como objetivo la interacción entre estudiantes, maestros y escuelas residentes para mejorar la capacitación de docentes de pregrado a través del desarrollo de proyectos que fortalezcan el campo de la práctica y lideren el Se graduó para ejercer activamente la relación entre la teoría y la práctica docente profesional, utilizando la recopilación de datos y diagnósticos sobre la enseñanza y el aprendizaje, entre otras didácticas y metodologías donde busca experiencias y estrategias, que propone una reflexión sobre los beneficios de PRP que induce mejora de la formación práctica del profesorado. Los residentes ayudarán a los maestros a aliviar estos problemas menores en la enseñanza y el aprendizaje. Brindar a los residentes una visión más amplia de cómo funciona un aula mostrando de alguna manera el comienzo de una nueva etapa en su vida laboral donde obtienen nuevas experiencias y mejoran sus prácticas. Después del registro y la aprobación del PRP, comenzó la primera fase de configuración donde se conocía la escuela en general, desde la gerencia hasta la cocina. La segunda fase fue la inmersión en las aulas, ayudando a los maestros y vinculando la teoría con la práctica. Esta fase facilitó el aprendizaje de los estudiantes y proporcionó a los residentes experiencias únicas. Este documento presenta proyectos desarrollados en la escuela sobre hábitos alimenticios, porque hoy en día hay más del $50 \%$ de los estudiantes que necesitan una reeducación alimentaria, porque comen muchos productos industrializados y también las dificultades que enfrentan los niños en el aula regular donde muestran Las dificultades y la superación. Este trabajo es de naturaleza cualitativa y contó con el respaldo bibliográfico de autores como FERREIRO (1987), LIBÂNEO (1996), VEIGA (2004), ZEICHNER Y CAIADO (1998).

Palabras clave: Programa de Residencia Pedagógica, Formación Docente, Mejora

\begin{abstract}
This article aims to present the objective of the Pedagogical Residency Program - PRP and aims at the interaction between resident students, teachers and schools to improve the training of undergraduate teachers through the development of projects that strengthen the field of practice and lead the graduated to actively exercise the relationship between theory and professional teaching practice, using data collection and diagnostics on teaching and learning, among other didactics and methodologies where he seeks experiences and strategies, which proposes a reflection on the benefits of PRP that induces improvement of practical teacher training. Residents will help teachers to alleviate these minor problems in teaching and learning. Providing residents with a broader view of how a classroom works by somehow showing the beginning of a new stage in their working life where they acquire new experiences and improve their practices. After the registration and approval of the PRP, began the first phase of setting where the school in general was known, from management to the kitchen. The second phase was immersion in classrooms, assisting teachers and linking theory to practice. This phase facilitated student learning and provided residents with unique experiences. This paper presents projects developed at school about eating habits, because today there are more than $50 \%$ of students who need to have a food reeducation, because they eat a lot of industrialized products and also the difficulties that children face in the regular classroom where they show the difficulties and the overcoming. This work is qualitative in nature and had the bibliographic support of authors such as FERREIRO (1987), LIBÂNEO (1996), VEIGA (2004), ZEICHNER and CAIADO (1998).
\end{abstract}


Keywords: Pedagogical Residence Program, Teacher Training, Improvement. Introdução

Este artigo relata a importância e as contribuições oferecidas pelo Programa Residência Pedagógica - PRP, constituído pela CAPES - Coordenação de Aperfeiçoamento de Pessoal de Nível Superior, e que pertence ao Ministério da Educação, criado em 2011 e implantado em 2012.

A instituição de ensino FACHUSC - Faculdade de Ciências Humanas do Sertão Central acolheu o programa e responsabilizou-se de encaminhar os selecionados para as escolas campos indicadas pelo programa. Este artigo foi construído com base nas vivências da Escola Municipal Dom Malan na cidade de Salgueiro-PE.

Além da importância e da contribuição, o programa objetiva aperfeiçoar a formação dos discentes de cursos de licenciatura por meio do desenvolvimento de projetos que fortaleça o campo da prática e conduzir o licenciado a exercitar de forma ativa a relação entre a teoria e a prática profissional docente, utilizando coleta de dados e diagnostico sobre o ensino e a aprendizagem escolar entre outras didáticas e metodologias. Esse programa também busca promover a adequação dos currículos e propostas pedagógicas dos cursos de formação inicial de professores da educação básica as orientações de Base Nacional Comum Curricular (BNCC).

O programa visa a interação entre residentes, professores e escolas buscando o aprendizado, unidos pelo mesmo propósito, o sucesso educacional. O PRP como projeto, tem na sua proposta que, os professores residentes frequentem um centro de excelência da educação básica na qual eles realizem atividades teóricas metodológicas, e tem como fundamentos o conceito de "imersão" e parceria na atividade prática entre diferentes instituições. Sendo assim, o programa não se limita somente a vivência em sala de aula, mas busca construir uma interação entre pesquisa acadêmica e teórica prática docente.

O programa possui muitos objetivos, entre eles, busca realizar com os estudantes um desenvolvimento metodológico e prático que integrem a política Nacional de formação de professores, trazendo meios de identificar metodologias, experiências e estratégias que propõem uma reflexão sobre os benefícios adquiridos no decorrer das vivências realizadas para desenvolver um aperfeiçoamento da prática.

Outro objetivo do PRP é aprimorar as práticas fortalecendo as vivências para promover uma formação de qualidade, o mesmo propõe uma vivência profissional aos professores da educação básica como uma proposta inovadora enfrentando muitos desafios e também inspirar os estudantes a desenvolver espaços de aprendizagem, referindo-se não 
apenas a modelos abstratos, mas considerar a vida e o trabalho como elaboração do convívio social possibilitando novos conhecimentos.

O Residência Pedagógica é muito importante, pois possibilita uma aliança entre residente do PRP, as escolas e preceptores, coordenadores e a gestão da escola, tornando-se mais fácil de sanar os desafios encontrados na formação dos estudantes, porque quando todos se comprometem facilita a aprendizagem dos estudantes.

A partir do $6^{\circ}$ período do curso de pedagogia começou uma nova fase de experiências para estudantes, pois o programa tem a função de aproximar a prática profissional da formação inicial. Mais do que isso, é importante salientar que facilita as vivências de modo mais articulado e significativo para todos.

Segundo Zeichner (1998):

[...] Um grande passo é ao tratar os professores como sujeitos, reconhecer que estes não estão buscando respostas fáceis ou receitas prontas, mas estão desejando ser desafiados intelectualmente e reconhecidos pelo que sabem e fazem. (ZEICHNER,1998).

Todos conhecem a importância do professor para desenvolvimento de uma criança. Sabem da relevância do docente dentro de uma instituição de ensino e que ele pode fazer a diferença ao fazer dos desafios, oportunidade para melhorar sua prática, sua metodologia, enfim, o seu fazer pedagógico.

O PRP trouxe a oportunidade para os licenciandos dos cursos de Pedagogia e de Ciências Biológicas de unir teoria à prática, de exercitar metodologias apreendidas em diversas disciplinas. Com isto, este artigo tem como principal objetivo, apresentar as vivências como residente na escola campo Dom Malan.

\section{Primeira fase: Ambientação escolar}

A Residência Pedagógica foi dividida em duas fases: a primeira de Ambientação e a segunda de Imersão. Para a primeira fase, o programa proporcionou o conhecimento da parte administrativa de uma escola. Consideramos importante este primeiro momento, pois na faculdade, conhece-se pouco do trabalho de uma gestão e do trabalho desenvolvido pela secretaria escolar.

Uma escola não é composta somente por salas de aulas, com professores e alunos, nem tampouco, áreas de laser para os momentos recreativos. Há uma demanda de documentos entrando e saindo diariamente de uma instituição de ensino. Esta fase possibilitou o conhecimento de documentos, como: Transferência, Histórico escolar, o registro mensal de 
frequência do aluno, entre outros. Porém, conhecer o PPP - Projeto Político Pedagógico da escola campo foi um momento de grande aprendizagem para os residentes, pois se ouvia apenas falar, mas sem conhecê-lo de fato.

Para Veiga (2004, p.13):

\begin{abstract}
O projeto busca um rumo, uma direção. É uma ação intencional, com um sentido explícito, com um compromisso definido coletivamente. Por isso, todo projeto pedagógico da escola é, também, um projeto político por estar intimamente articulado ao compromisso sociopolítico, com os interesses reais e coletivos da população majoritária. É político no sentido de compromisso com a formação do cidadão para um tipo de sociedade. Na dimensão pedagógica reside à possibilidade da efetivação da intencionalidade da escola, que é a formação do cidadão participativo, responsável, compromissado, crítico e criativo. Pedagógico, no sentido de definir as ações educativas e as características necessárias às escolas de cumprirem seus propósitos e sua intencionalidade. (VEIGA, 2004, p.13).
\end{abstract}

Esse documento tem elaboração anual obrigatória pela legislação, de acordo com a LDBEN n 9.394/96, Lei de Diretrizes e Bases da Educação Nacional. Essa obrigatoriedade tem como pano de fundo a possibilidade de que todos os membros envolvidos na comunidade escolar tenham acesso ao projeto, podendo dele participar e nele interferir sempre que necessário, a fim de que seja fruto de uma construção democrática.

\title{
Segunda fase: Imersão escolar
}

Esta fase é o ponto central do Programa de Residência Pedagógica, pois leva o graduando em licenciatura, na metade do curso, a entrar na sala de aula, o que é para o residente, um campo de fazer e aprender.

Vale salientar que a residência é um estágio aperfeiçoado e que abre portas para o futuro professor conhecer o trabalho do professor que o observa e de contribuir com ele para o desenvolvimento da turma. Esta etapa é para refazer o que não está dando certo, é para rever metodologias e a prática geral. A fase de imersão induz o aperfeiçoamento da prática de ensino.

\section{Principais dificuldades encontradas na escola campo}

Muito se observa ao realizar um estágio supervisionado e com a residência pedagógica, o grau de observação é maior, tendo em vista a duração do programa que é de 24 meses. Pode-se observar questões a respeito de dificuldades na leitura, hábitos alimentares e Educação Inclusiva. Buscou-se então, um aprofundamento teórico nestas temáticas para um melhor entendimento: 


\section{a) As dificuldades na leitura}

As dificuldades de leitura são tidas como um dos maiores obstáculos enfrentados pelos alunos, preocupando os professores em sala de aula, que buscam métodos para que haja um bom desenvolvimento da leitura, pois uma vez que o estudante desenvolve a leitura ele consegue interpretar e compreender várias coisas.

Para Caiado (2019?) segundo pesquisas, as escolas públicas apresentam maior índice em relação a dificuldade com a leitura, porém vale ressaltar, que tas realidades se faz presente em todas as instituições de ensino independentemente do segmento (publico ou privado).

É importante saber lidar com essas situações enquanto educadores, ter a consciência de que as dificuldades apresentadas na leitura estão intensamente ligadas ao desenvolvimento da habilidade escrita. Em sala de aula e na escola algumas estratégias são aplicadas para facilitar o desenvolvimento no processo de leitura, uma das estratégias é colocar no livro paradidático onde eles irão ler o que eles quiserem e em seguida é feito a escrita de textos no quadro onde desenvolve a escrita e também a leitura do livro didático, tornando uma leitura prazerosa e menos cansativa.

Incentivar os estudantes a lerem livros pequenos e sempre deixá-los levarem livros paradidáticos para casa onde terão mais tempo para fazer a leitura e de preferência no final de semana onde podem ler várias vezes, facilitando a compreensão dos estudantes, e no inicio da semana fazer a apresentação de cada leitura. Outra estratégia é a decomposição de frases ou sílabas onde facilita a aprendizagem. Juntar duplas onde um já tenha o domínio da leitura com outro que tenha esse domínio incentiva bastante fazendo com que o outro consiga desenvolver a leitura. São várias as estratégias que podem ser usadas em sala de aula, além dessas formas de incentivo, a família é o ponto principal para ajudar suas crianças porque se trabalha na escola e ter o reforço em casa torna-se mais eficaz e assim, diminuir essas dificuldades, facilitando a vida do professor.

Segundo Ferreiro e Palácio (1987), o ato de ler é beneficiado de uma variedade de opções, "o leitor não responde simplesmente aos estímulos do meio, e sim, desenvolve estratégias para trabalhar com texto de tal maneira que seja possível compreendê-lo". O hábito da leitura é de suma importância porque é através da leitura que se abre novos horizontes onde tornamos capazes de aprofundar os conhecimentos sobre o mundo e torna se um cidadão crítico e conhecedor dos seus direitos.

A família é fundamental em todas as etapas da vida da criança, desde então, no processo de alfabetização e letramento ela é muito mais importante e significativa, por se 
tratar de uma etapa extraordinária na vida da mesma, é imprescindível que a família esteja junta com a criança, desde pequeno, ir lendo histórias para ir despertando o gosto pela leitura.

Nada adianta a escola aceitar o aluno como ele é, se essa mesma escola e seus educadores não se esforçarem para modificarem práticas pedagógica e adequarem recursos e metodologias, necessidades de aprendizagem dos alunos como também, não oferecem materiais concretos e instrumentos necessários para os educandos enfrentarem, suas dificuldades de leitura e de escrita no âmbito educacional. É preciso, portanto, que a escola possibilite aos alunos o acesso amplo ao conjunto de conhecimentos historicamente produzido pela sociedade, como a leitura.

\section{b) Os hábitos alimentares}

Falar sobre a alimentação durante o período em que as crianças estão na escola é muito importante. Foi pensando nisso, que este espaço foi aproveitado. É interessante também que os próprios estudantes recebam a informação necessária sobre os lanches realizados e o bom e saudável hábito de alimentar-se corretamente.

Durante essas vivências na escola observou-se o quanto os estudantes precisam de reeducação alimentar, pois muitos deixam de comer o lanche oferecido pela instituição para comprar pipocas, refrigerantes e doces, tornando sua saúde comprometida. Esses hábitos inadequados começam muito cedo, em idade pré-escolar e no seio da família é uma situação de preocupação, porque através desses maus hábitos as crianças ficam com o índice de massa corporal elevada, basta salientar que as ações de prevenção das principais doenças crônicas devem dizer que a alimentação inadequada é a principal responsável pelos anos de vida saudáveis perdidas e que a má alimentação é um dos fatores contribuintes para o surgimento de doenças crônicas não transmissíveis, que antes eram restritas à idade adulta, mas hoje já estão aparecendo em idade cada vez mais precoces.

Desde a infância é preciso ter uma alimentação saudável e é justamente na infância e na adolescência que os hábitos e os comportamentos alimentares são voltados para determinados tipos de alimentos. Sabores e texturas são formados, já foi comprovado que alguns fatores que levam ao desenvolvimento da obesidade, por exemplo, são genéticas e não podem ser alterados, devendo ser apenas bem supervisionados. Fora estes, a família, a escola, os diferentes ambientes frequentados pelas crianças, e a sociedade, principalmente no que diz respeito a cultura alimentar da região, exercem papel decisivo na formação do padrão salvo intervenções eficazes, pelo resto da vida. 
É importante atentar para alguns fatores desde o primeiro momento de inclusão de alimentos, para que sejam formados hábitos alimentares saudáveis. É importante que o padrão alimentar que está sendo instituído em casa, em se tratando de padrão saudável, seja compartilhado pela escola e pelo cuidador da criança (babá, avó ou outro familiar) para que a criança entenda que aquele é o mais adequado e não que algum dos ambientes está privando-o de determinados prazeres alimentares.

Os meios de comunicações influenciam bastante não só pela propaganda mais também pela curiosidade por experimentar tais produtos como também pela divulgação de conceitos errôneos sobre alimentação, nutrição e hábitos alimentares.

\section{c) Educação Inclusiva}

A história da Educação Inclusiva inicia-se com a declaração de Salamanca, documento formulado na Espanha que discute a exclusão dos diferentes tipos de deficiências dentro do espaço escolar. $\mathrm{O}$ documento aponta a necessidade de uma escola para todos, levando a um movimento mundial de reflexão sobre os processos excludentes dentro da escola. No Brasil começa na década de 70, quando algumas escolas passam a aceitar alunos especiais, desde que os mesmo conseguissem se adequar ao plano de ensino da instituição.

A criança com deficiência na sala de aula muitas vezes são descriminadas por seu comportamento, incapazes de aprender, mas vale salientar que são humanos também e têm os seus direitos assegurados por lei.

A lei $N^{\circ} 7.853$ de 24 de outubro de 1989:

Dispõe sobre o apoio as pessoas portadoras de deficiência, sua interação social,
sobre a coordenadoria Nacional para integração da pessoa portadora de Deficiência
- Corde, institui a tabela Jurisdicional de interesses coletivos ou difusos dessas
pessoas disciplina a atuação do ministério público define crimes, e dá outras
providencias. (BRASIL, 1989)

Pode-se observar que temos leis que asseguram os direitos, mas na prática muitas crianças com deficiências são descriminadas, se sentem desvalorizados. Nos espaços escolares, cabe à escola, conscientizar seu público para respeitar as diferenças. Disponibilizar momentos de interação para que essas crianças sintam-se incluídas no processo de ensino aprendizagem e em todo o espaço escolar.

Todas as crianças são capazes de aprender: esse processo é individual e o professor deve estar atento para as necessidades dos alunos. Crianças com deficiência auditiva e visual desenvolvem a linguagem e pensamento conceitual. Alunos com deficiência mental podem 
enfrentar mais dificuldade no processo de desenvolver oralidade e recolher sinais gráficos. É importante a diversidade e estimular as crianças a apresentar seu melhor desempenho. A avaliação deve ser feita em relação ao avanço do próprio aluno, sem usar critérios comparativos.

A Declaração Mundial de Educação de 1990, é uma resolução das Nações Unidas que trata dos princípios, política e prática em educação especial. Adotada em assembléia geral, apresenta os procedimentos padrões das Nações Unidas para qualificação de oportunidades para pessoas com deficiência sendo considerada mundialmente um dos mais importantes documentos que visam a inclusão social, juntamente com a Declara de Salamanca (1994).

As escolas do ensino regular devem educar todos os alunos, enfrentando a situação de exclusão escolar das crianças com deficiência das que vivem nas ruas ou que trabalham, das superdotadas em desvantagem social e das que apresentam diferenças linguísticas, étnica ou cultural. Com esses conhecimentos sobre a educação inclusiva e sobre as leis que acobertam as pessoas com deficiência tem os mesmos direitos e liberdade fundamental que as demais pessoas, definindo como descriminação toda diferenciação ou exclusão possa impedir ou anular o exercício dos direitos humanos e da liberdade.

\section{Metodologia}

Os métodos utilizados para desenvolver esse artigo partiram de observações na escola campo de estágio, com fase de Ambientação e após seu término, com a fase de Imersão na sala de aula, com projetos construídos e vivenciados e através de diálogos voluntários com professores e estudantes.

Este trabalho teve natureza qualitativa, com uma pesquisa bibliográfica visando a fundamentação dos principais assuntos abordados no trabalho. A escola de residência se tornou além de um campo de atuação, um verdadeiro campo de pesquisa.

\section{Resultados e Discussão}

Esse trabalho foi desenvolvido baseado através das vivências na escola campo. As experiências vividas dentro do Programa Residência Pedagógica - PRP foram de grande importância para o desenvolvimento profissional. Os resultados adquiridos contribuirão tanto para os trabalhos em sala de aula como também para todo o universo escolar.

O Programa Residência Pedagógica teve seu inicio de inscrição no dia 30/07/2018. De início, os estudantes tinham que realizar inscrição na Plataforma Freire e em seguida escrever uma carta de motivação, demonstrando interesse em participar no programa, uma espécie de 
justificativa para seu ingresso no PRP, suas características pessoais e seus conhecimentos sobre as escolas de educação básica entre outros. No dia 09 de agosto de 2018, o programa apresentou o resultado final da seleção. Muitos residentes conseguiram bolsas e outros ficaram como voluntários. Após a seleção, reuniões foram marcadas para o início da residência e momentos com o diretor da FACHUSC - Faculdade de Ciências Humanas do Sertão Central, o Coordenador do programa, Preceptores, mostrando a importância do programa para a faculdade, para os residentes, e demais envolvidos.

A fase de ambientação proporcionou o conhecimento da parte burocrática e administrativa de uma instituição de ensino, destacando o conhecimento de vários documentos. A fase inicial possibilitou conhecer, além do espaço físico e cada ambiente, a gestão da escola e demais funcionários. Dentro da referida etapa, foi analisado o PPP Projeto político Pedagógico da escola e nele, observou-se o empenho da instituição em realizar um trabalho de qualidade.

Durante essa primeira etapa de estágio, foram realizados estudos e observações em documentos importantes na secretaria, com isso, pode-se desenvolver uma atividade que mereceu bastante atenção por se tratar de documentação relevante. As atividades desenvolvidas nesse espaço foram: fazer matricula de estudantes, anexar documentos nas fichas de matrícula, preencher ficha de referência, auxiliar na ornamentação da escola para receber os estudantes, entre outros. Foram momentos de novas aprendizagens e que certamente veio para aprimorar os conhecimentos.

A fase de imersão foi bem maior, pois está associada diretamente ao fazer pedagógico. O mais importante é saber que durante a socialização das muitas atividades realizadas durante a imersão, os estudantes compreenderam a importância de cada momento vivenciado, afirmando que todos os resultado foram positivos.

A segunda etapa de estágio foi na sala de aula juntamente com os professores das turmas, esses se tornaram os supervisores das atividades desenvolvidas pelo residente, onde foi desenvolvido um trabalho colaborativo com propostas, dinâmicas, tanto da professora da turma quanto da gestão escolar, tornando mais fácil a compreensão dos estudantes.

Durante o segundo momento de residência, surgiu a oportunidade de acompanhar duas turmas de $3^{\circ}$ ano, ambas com um grande número de alunos, mas diferem na questão do aprendizado. Sabendo disto, as professoras se mostraram preocupadas com a leitura dos alunos, sempre buscando formas para o desenvolvimento da leitura. Por este fato, sempre estão construindo projetos de leitura e disponibilizando diariamente livros para a sala, com dinâmica de leitura onde os colegas que já sabem ler são colocados em duplas com aqueles 
que têm certo domínio, esta atitude motiva bastante porque eles sentem capazes de conseguir desenvolver a leitura. Durante esses momentos de leituras procurei auxiliar os estudantes, principalmente aqueles que não sabiam ler, buscando metodologias junto com a professora para que eles se sentissem capazes de desenvolver a leitura.

A maior conquista foi obtida com os projetos relacionados a leitura. No início, uma turma com 35 alunos, 18 já sabiam ler e 17 ainda não tinham avançado, mas com o auxílio das residentes e os projetos e atividades aplicadas, esta realidade mudou, muitas crianças se envolveram e desenvolveram a leitura, concluindo a fase com apenas 5 estudantes ainda não totalmente alfabetizados, mas pode-se dizer que já se encontram silabando e melhor, desejam aprender a ler e a escrever.

Durante as vivências em sala de aula foram desenvolvidas inúmeras atividades entre elas estão: leitura de literaturas diversas, definir o sentimento da palavra ou expressão em diferentes gêneros, perceber as tradições religiosas que fundamentam os textos sagrados.

Segue alguns registros de experiências: Resolver problema do campo aditivo utilizando algoritmo; Identificar as diferentes possibilidades de ação rítmica no andar, balançar, saltar, girar, desafiando ações lúdicas; Roda de leitura; Principais partes das plantas, ilustração de um vegetal complexo, montagem no mural; Exploração sobre o trajeto de casa à escola destacando os pontos de referências, Roda de conversa e atividade no caderno; Interpretação de pequenos textos destacando a importância do uso da letra maiúscula no início da frase; Alimentação saudável, lista com alimentos saudáveis em seguida atividade; Antecessor e sucessor; A colonização do Nordeste; Poema "Minha Escola", atividade sobre o poema Geografia com o conteúdo paisagem natural e modificada, destacar as paisagens naturais e modificada, desenhar algumas paisagens; A galinha Anita e os seis pintinhos e logo após os alunos foram fazer o reconto de acordo com o entendimento de cada um.

Todos os registros de aulas citados possibilitaram a aprendizagem organizacional de um plano de aula, pois cada um deles contemplava: justificativa, objetivos, procedimentos, recursos e avaliação. Foi muito importante conhecer a construção de cada uma das etapas de um planejamento de aula.

Além das dificuldades de leitura já citadas, no decorrer das muitas vivências em sala de aula outro ponto chamou atenção: as dificuldades que as crianças com deficiência enfrentam em relação ao convívio e à aprendizagem. Confirmou-se que existem dificuldades dentro das salas de aula em relação às deficiências. Diante de algumas necessidades observouse que ainda há quem não compreenda a importância da inclusão para a sociedade e o quanto a pessoa incluída sente-se bem em participar do universo escolar. Diante disso, foi preciso 
desenvolver atividades onde os alunos compreendessem o quanto é importante respeitar as deficiências dos outros, pois se sabe que todos devem ser respeitados. Foram desenvolvidas atividades como palestras, vídeos, dinâmicas, aonde eles iriam se colocar no lugar das pessoas com deficiências. Essas experiências serviram para eles repensarem suas atitudes.

Outro problema enfrentado pela escola é sobre os hábitos alimentares da maioria dos estudantes. Muitos não fazem a refeição oferecida pela escola, preferindo trazer seu próprio lanche. O perigo está justamente neste ponto, pois foi observado que $90 \%$ dos alimentos trazidos de casa não são saudáveis, pobres de vitaminas e nutrientes. Os que não trazem seu alimento costumam comprar seu lanche na escola.

Visando mudar esta realidade, a escola construiu um projeto sobre hábitos alimentares saudáveis. Várias atividades foram desenvolvidas, como: conversas com os estudantes, mostrando a importância de se alimentar com produtos que contenham nutrientes importantes para o organismo, vídeos apresentando os problemas que os alimentos industrializados causam em nosso organismo.

Observou-se que a Dom Malan é uma escola que está sempre de portas abertas buscando a inclusão de todos e busca sempre proporcionar uma educação digna, comprometida com o crescimento físico e cognitivo do alunado. Para Libâneo (1996, p. 152 153), a escola que consegue elaborar e executar num trabalho cooperativo; seu Projeto Político Pedagógico dá mostras de maturidade de sua equipe, de bom desenvolvimento de toda comunidade escolar.

A maior obrigação da escola é educar e sabe-se que ela é um dos fatores responsáveis pela transformação e evolução da sociedade, por tanto, precisa-se dar a contribuição, pois ela ajuda os educandos a "abrir os olhos" no sentido de perceberem e defenderem seus direitos perante a sociedade.

\section{Conclusões}

Foi um grande privilégio participar como residente do PRP - Programa Residência Pedagógica da CAPES. Receber o programa na FACHUSC foi um marco histórico e fazer parte dele será eternizado nos currículos dos residentes, principalmente por ser a primeira turma a receber o programa.

Todo o trabalho desenvolvido foi vivenciado com muita dedicação, sempre buscando contribuir de forma positiva e clara onde facilitasse a compreensão dos estudantes e consequentemente o entendimento. 
A residência proporcionou a união da teoria com a prática, acrescentado momentos de aprendizagens que certamente serão levadas para as salas de aulas, pois toda a experiência adquirida com o programa gerou o aperfeiçoamento além da convicção de ter escolhido o curso certo.

O estágio/residência é uma ferramenta necessária para o início da operação a ser realizada pelo profissional aprendiz de um curso de Licenciatura, que será um futuro professor. É um instrumento de aquisição de uma nova realidade, pois vivenciamos novas experiências que nos mostram a realidade da nossa futura profissão, através de uma forma mais técnica e profissional.

Conclui-se que houve mudança no papel do professor e também do aluno. O professor deve ter como função estimular amplamente a busca de novos conhecimentos, ou seja, está atualizado e reciclado de acordo com as mudanças tecnológicas, sociais, culturais, econômicas e políticas. Percebe-se que a formação do professor também deixa muito a desejar. O educador não está preparado para esses novos tempos.

Há de confirmar que muita coisa mudou, mas não o bastante. Existem dificuldades para colocar em prática as novas concepções e os novos modelos. É preciso estar aberto às novidades e procurar diferentes métodos de trabalho, mas sempre partindo de uma análise individual e coletiva das práticas.

\section{Referências}

BRASIL. Lei de Diretrizes e Bases da Educação Nacional. Lei № 9.394 de 20 de dezembro de 1996.

BRASIL. Lei $\mathbf{n}^{\circ}$. 7.853, de 24 de outubro de 1989. Dispõe sobre o apoio às pessoas portadoras de deficiência, sua integração social, sobre a Coordenadoria Nacional para Integração da Pessoa Portadora de Deficiência, institui a tutela jurisdicional de interesses coletivos ou difusos dessas pessoas, disciplina a atuação do Ministério Público, define crimes, e dá outras providências. Diário Oficial da União. 25 out 1989.

CAIADO, Elen Campos. Como orientar os alunos com dificuldades na leitura. (2019?) Disponível em https://educador.brasilescola.uol.com.br/sugestoes-pais-professores/comoorientar-os-alunos-com-dificuldades-na-leitura.htm. Acesso em 20/08/2019.

FERREIRO, Emilia; PALACIO, Margarita Gomes. Os processos de leitura e escrita: novas perspectivas. Traduzido por: Luiza Maria Silveira. 3 ed. Porto Alegre: Artes Médicas, 1987.

LIBÂNEO, José Carlos. Organização e gestão da escola: Teoria e Prática. Goiás: Alternativa, 1996

ONU. Declaração Mundial de Educação. 1990. 
ONU. Declaração de Salamanca. 1994.

VEIGA, Ilma Passos A. (org.). Projeto político-pedagógico da escola: uma construção possível. Campinas: SP.Papirus, 2004.

ZEICHNER, Kenneth M. Para além da divisão entre professor-pesquisador e pesquisador acadêmico In: GERALDI, Corinta M.; FIORENTINI, Dario \& PEREIRA, Elisabete M.

(orgs.) Cartografia do trabalho docente: professor(a)-pesquisador(a). Campinas, Mercado de Letras?ABL, 1998. pp. 207-236. 